\title{
FACTORS OF REALIZATION AND DIFFERENTIATION SCIENTIFIC POTENCIAL OF YOUNG SCIENTISTS
}

\author{
KATYA SHELESTUN \\ skatyusha@bigmir.net \\ Taras Shevchenko National University of Kyiv, \\ Ukraine
}

\begin{abstract}
In domestic and foreign scientists' research the scientific potential is investigated through a series of economic indicators, but social and cultural aspects are not revealed. Scientists' interest focuses primarily on the resource component of the scientific potential expressed through quantitative indexes (funding of science, number of academic staff involved in economics, the volume of scientific \& technical work, etc.). The analyses of the current scientific literature have found that the concept of scientific potential with respect to young scientists has not been sufficiently studied.

Key words: the factors of realization of scientific potential, the factors of differentiation of scientific potential, scientific products, scientific potential of young scientist.
\end{abstract}

The practice of recent decades shows that societies that can effectively accumulate and make productive use of their scientific potential will have the strategic advantage. The major carriers of scientific potential are young scientists. European Studies data prove (GlobSci survey ${ }^{1}$, Nature survey) that young researchers are not only specialists who have professional knowledge, skills and abilities, but also the people whose scientific activity allows to develop innovative ideas, a new way to solve current problems of the country. The young scientists are more receptive and adapt faster to social and economic changes of the state, are more mobile in the global scientific space and socially active than the older generation of scientists.

The purpose of the paper is to develop a theoretical model for studying subjective components which effect the realization of scientific potential. Scientific problem: There is a lack of sociological knowledge about the power of the scientific potential of young scientists in subjective dimensions.

The subjects of study are young scientists who are active in the process of constructing their own social position in the field of science. Structural terms referring to a group of young scientists are age and functional and positional characteristics. The main structural characteristics that differentiate scientific potential of young scientists are marital status, presence of children, financial situation, living conditions, gender, age and social background.

In the beginning of the study of the phenomenon known as "scientific potential" we are faced with some confusion when the same scientific studies use different categories as synonyms, such as "potential" and "capital". From the Latin

The "Global Science" Research Project, conducted by Chiara Franzoni; Giuseppe Scellato; Paula Stephan 
term "potential" is interpreted as "possible with the implementation of necessary conditions". As a result, scientific potential is the ability to obtain and use information and knowledge, whereas scientific capital is a functional component of the scientific potential. Scientific capital is the knowledge, skills and experience inspired by intellectual activity that is a form of intellectual abilities to create new, previously unknown knowledge. Today in social sciences two approaches to the study of scientific potential are defined - micro and macro levels of study.

The macro-level theories focus attention on resources and institutional components of scientific potential. This level includes economic theory (Peter Drucker, Ralf Dahrendorf, Joseph Shumpetter, etc.) which investigates the scientific potential through quantitative indicators (number of academic sectors, the amount of spending on science and research, export-import of high technology, the cost of innovation), theory of innovations and developments (Henry Etzkowitz), neo-institutional (new institutionalism) theory (Douglass C. North, Mark Granovetter, Douglas McGregor, etc.). According to these theories, scientific potential forms resources, formal and informal rules of access to resources, actors and strategies of their actions.

Realization of scientific potential is affected by such factors and institutions as the government, economics (market mechanisms) and science institutions. Such institutions and factors as the government and economics can create or limit the conditions for the development and realization of scientific potential. The government is able to create institutional conditions for the science development through programs and strategies (science and innovation policy). The main actors at the state level are the political leaders that define the vector of development, constitute the programs and determine the strategy for the development of priority (from their perspective) areas of the country. The main actors in the economic sphere can implement scientific products on the market through market mechanisms. The institutions of science (academic institutions) are the location and the accumulation of scientific potential, undergoing research and they create science products.

The micro-level theories focus attention on personal features of scientists (personality and cognitive characteristics). This level includes such conceptions as: "class of knowledge" by Deniel Bell, "creative class" by Richard Florida, "knowledge workers" by Alvin Toffler, "class of intellectuals" by Vladislav Inozemtsev, "post materialists" by Ralph Inglehart. R. Florida is a contemporary American scientist who studies scientific potential through scientific activity (mobility, training, study, applying knowledge to practice). He also proved that the main motives of scientific activity are personal interest and creative challenge. Alex Lem (Royal Holloway, University of London) also pointed out the importance of individual motivational factors. She divided the scientists according to the dominant motives into those who want financial compensation, reputation or career achievements and inner satisfaction. Russian scientist Evgen Ilyin conducted research and identified the main motivations of scientific activity:

- epistemological - the pursuit of knowledge and the creation of something new (need for creative activity);

- $\quad$ cognitive - the desire to understand the phenomenon and reveal its essence;

- $\quad$ altruistic - to bring benefit to society by opening new ways; 
- career motivation - the desire to get a high position,

- recognition - the desire of glory, the desire to stand out among others;

- material - the desire of wealth.

American scientist Robert Merton pointed to the importance of such motive of scientific activity as recognition from colleagues. Russian scientist Evgen Iljin indicates successful scientific career as an important motivational component of scientists, especially the young ones.

An important resume of the outlined theoretical approaches was the concept of constructive structuralism by Pierre Bourdieu ${ }^{2}$, which includes the achievements of these two approaches (macro and micro theories). At the heart of the scientific study of the potential of scientists is the concept of constructivist structuralism by P. Bourdieu. Structuralism implies the existence of objective structures which can stimulate or inhibit desire and action (resources and positions) of actors, created by institutions. Constructivism is a theory based on observation and scientific considerations of not only objective structures but also personality characteristics of actors.

The election of constructivist structuralism theory as a framework of study is conditioned by key ideas: homology position of actors in the social space, a symbolic struggle for allocation of capital between actors, duality position of actors in social space ${ }^{3}$.

Fields homology. Social space contains various fields that are mutually agreed upon and each with its own logic of development. The field of science is in homology (in relation) with the field of politics and business. The scientific potential of the subject is realized within the field of science as one of the structural components of social space. "Field" - is a system of objective relations between positions of actors in social space. The position of an actor (a person) in social space is socially determined and does not depend on physical existance. Social space is represented by a set of fields that interact (homology relationships) or conflict with each other. The field of politics affects scientific discourse by selecting priority direction of research, contribution in the field of science and the shaping of scientific discourse at the level of scientific activity. The main actors in the field of economy are enterpreneurs who can make sufficient contributions for scientific development, put scientific findings (products) into practice and in this way t develop economy in the country. Thus, the field of science is made up of the relationships which individuals enter to produce scientific products due to scientific activity. Scientific products are important for science, politics and business activities. It causes the correlation of main actors' positions in these three fields.

According to P. Bourdieu theory capital is an important functional component of the scientific potential of the subject. Capital structures the relationship and defines the position in the social space. He attached importance to the cultural capital which can exist in three types:

- incorporated condition - a set of relatively stable dispositions, reproducible and demonstrated skills (goal setting and determination of the means for their realization through knowledge, abilities, skills);

Pierre Bourdieu (1930-2002) was a French sociologist, anthropologist and philosopher.

Bourdieu, P. (1986): The Forms of Capital, in: Richardson, J. G. (ed.): Handbook of Theory and Research for the Sociology of Education, New York/Westport/London, pp. 241-258. 
- objective condition - taking capital materialized forms are available in observation and transfer them to the physical, visual form (the results of research activities);

- institutionalized condition - recognition of this form of capital in social space (recognizing the products of scientific activity both within the state and at the international level).

Cultural capital refers to assets, e.g. competencies, skills, qualifications, which enable holders to mobilise cultural authority and can also be a source of misrecognition and symbolic violence.

The actors in the field of economy hold economic capital, which represents a type of power or status. Economic capital is necessary for the field of science because it is the financial and material support for research activities. Symbolic capital is a kind of social capital associated with the presence of authority, recognition and prestige position in the structure of the field of science (at the important subjects in science) and beyond. P. Bourdieu sees symbolic capital (e.g. prestige, honor, attention) as a crucial source of power.

The main types of social power are supported by these three types of capital. Economic and cultural capital can be symbolic when it becomes known or recognized. These capitals crystallize at the field and in the agents who hold certain positions according to their available capacity and capital structure. Uneven distribution of capital leads to competition or struggle. As a symbolic struggle for access to resources, capital is expressed in practical ways - as capital (economic and cultural) and as the status and position in the field (symbolic capital).

In consequence of the dual structuring of social reality, the position of an agent in the field of science is formed by subjective and objective manifestations (duality positions):

Objective positions that actors occupy in the structure of the fields of science, which are caused by functional (professional credentials), social status characteristics, volume and structure of available capital.

Subjective positions (dispositions) - the perception of an agent's own position. This perception is based on habitus. An agent's habitus is predicted by capital (volume and structure) and the place position which he occupies in the structure of the field.

Habitus is the real position of the agents in the field of science, which determines sets, ideas and behaviors which condition their actions (strategy). Behavior strategies are a system of agents' practices which can be seen as a compromise between the status and the aspirations of the real possibilities of the agents. Implementations of scientific potential depend on the capacity and structure of its capital and the starting position of actors (position in the field of science), personal settings, and intentions, motives, values and conditions for research activities.

So, based on the conceptual framework of the article key concepts and the system of indicators (objective and subjective components of the scientific potential of young scientists) were worked out. Summarizing the theoretical approaches, we conceptualized such manifestations of scientific potential as: 
- Factors of realizations;

- Factors of differentiating;

- Volume of scientific potential;

- Scientific products.

The factors of realizations of the scientific potential of young scientists are expressed through value-motivational components of scientific activities and cognitive-praxeological abilities of subjects in scientific activity. Values, perceptions, priorities, guidelines form the orientation of the potential of scientists which is manifested in their behavior. The value-motivational component of scientific activity is measured through the following indicators: "the factors of attractiveness of research activities", "the factors of engagement in research activities" and "satisfaction with different aspects of research activities". The cognitive-praxiological abilities are expressed in presentation skills, communication skills with using professional vocabulary, language skills of young scientists. Languages are an important factor of the involvement of scientists in international scientific cooperation and allow young scientists to learn from the experiences of their foreign colleagues.

The factors of differentiating scientific potential of young scientists. There are two levels of the differentiating of scientific potential, which are expressed through organizational and structural indicators.

Table 1. Two lewels of the differentiating of scientific potential.

\begin{tabular}{|l|ll|}
\hline Organizational indicators & $\begin{array}{l}- \\
\text { technical and informational resources); } \\
\end{array}$ & factors of mobility \\
\hline Structural indicators & - & marital status, \\
& - & presence of children, \\
& - & income, \\
& - & accommodation, \\
& - & gender, \\
& - & age \\
& - & ascription \\
\hline
\end{tabular}

Source: Own Table.

The indicator of mobility is a transition from one social scientist position to another. This is measured through such indicators as "Satisfaction with the terms of professional and official promotion", "prospects for professional growth" and "favorable brainpower". The indicator of "ascription" gives information about the parents of young scientists (education, job, occupation, profession, position). To wide extent, mobility of scientific personnel is the ability of scientists to change specialization, research object, place of work, residence and so on. Russian researcher Irina Popova discussed in her research the negative trends in science, explaining their two reasons - loss of interest due to not enough funding and prestige of science by young scientists and aging research teams.

The volume of scientific potential causes the creation and implementation of the scientific potential of subjects. It is measured through formal indicators of sci- 
entific potential and it makes it possible to evaluate the general conditions established for the implementation of the scientific potential of subjects at the state level (policy of promoting scientific research, funding of research activities) and the level of the economy (science parks, indicators of "innovation activity of Ukraine", "Implementation of innovations in industry", "spending on the development of scientific and technical fields"). The main organizational forms of interaction between science and economy (business corporations) are science parks. Science park ("university research park" or "science and technology park") is a unit that supports university, industry and government collaboration with the intent of creating high technology economic development and advancing knowledge. One of the main principles of the Park is to create an enabling environment for research activities. The main actors of innovation in a science park are young scholars - students and postgraduate students. There are two key parks in Ukraine: Kyiv Polytechnic and Corporation Science Park Kyiv National Taras Shevchenko University. At the level of scientific institutions it is measured through such indicators as human resources, international cooperation, research grant funds and publishing activity. By studying the activity of science parks in Ukraine it was found that they produced a small number of innovative products in comparison with developed countries (Silicon Valley, Technology Park in Orleans, Manchester Science Park), and the organizational innovation was improved very slowly.

Scientific products are the end result of research activities and practical use of cognitive and personality praxiological structures of young scientist. It is the main indicator of the realization of scientific potential. Key preconditions for a scientific product are the volume of scientific potential and the factors of differentiation of scientific potential. The research productivity of scientists is measured through formal statistical indicators of scientific activity (the number of scientific publications, presence / number of citations, participation in scientific conferences, participation in international programs, awards and scholarships for successful scientific activity).

Based on the conceptual framework of study we defined the concept of scientific potential as abilities and orientations of young scientists to produce scientific products competitive in market interactions in the field of science.

Data statistics analysis of Ukraine show that institutional capacity (at the level of science and innovation policy) in comparison with the developed countries of the European Union and the "The Big Eight" has a number of problems, such as poor awareness on the institutional system-level (level of the ruling elites) of the importance of building a knowledge-based society and the lack of a balanced budget policy to support the development of knowledge-intensive sectors of society. The level of funding for R\&D (Research $\mathcal{E}$ Development) and technology areas (basic science, applied research and development) in Ukraine steadily decreases with time. Due to the dynamic aspect of science funding in Ukraine, every year fewer funds are allocated from the state budget for the development of science. If in 1998 year the amount of funding for science was 1.21\% of GDP, in 2012 year it was only $0.73 \%$ of GDP. In such developed countries as Japan in 2012 the rate of funding for science was 3.33\% of GDP, in the U.S. - 2,79\% of GDP, Germany - 2,78\% and the EU-27 - 1.9\% of GDP. 
In the main programs of developments (Okinawa Charter on Global Information Society, program of UNESCO, Framework programmes for research and technological development) the importance of fundamental and applied research was indicated. In Ukraine the funding of R\&D exceeds fundamental and applied research, given the fact that they are the theoretical and practical base of R\&D. Thus, 2188.4 million were allocated to fundamental research in $2012,1617.1$ million to applied research and up to 5037 million to R\&D. Instead of investments in applied research the funds are invested in developments that find their realization abroad rather than in Ukraine. This negatively affects the activity of technical universities and leads to the death of fundamental science.

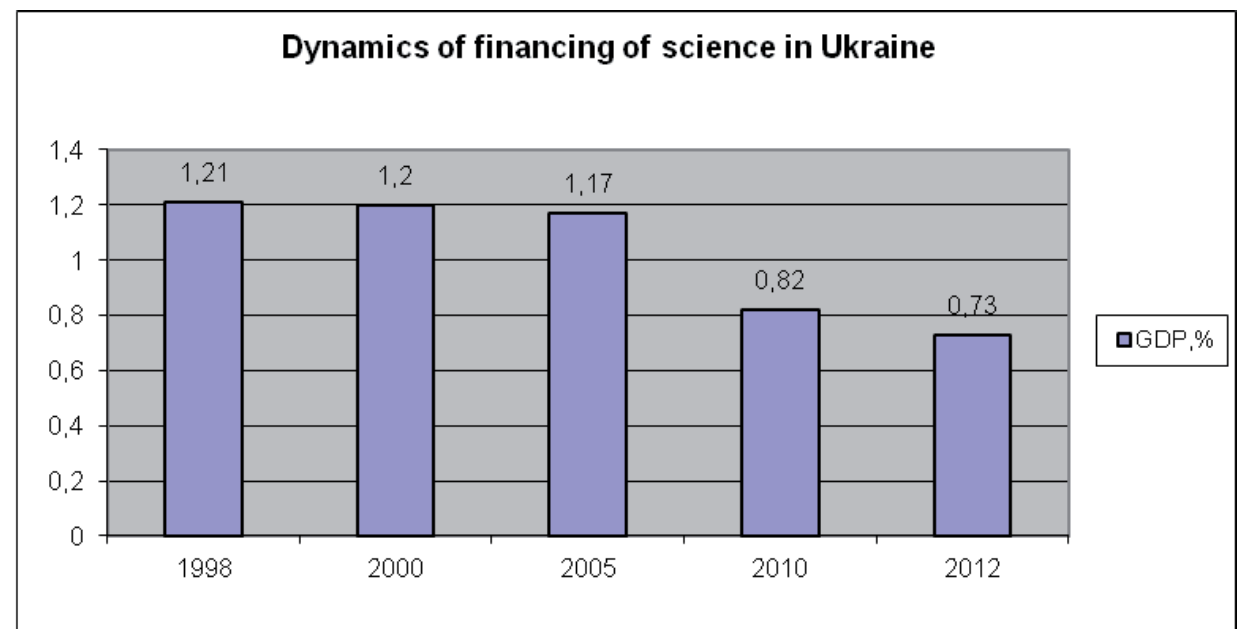

Chart 1. The dynamics of science funding in Ukraine;

Source: The figures given in the chart are the sum of budget and extra-budgetary funds allocated to science in a year ${ }^{4}$

Given the fact that scientists are the main "producers of scientific knowledge" it is very important to look at the indicator of "saturation of scholars" in comparison with other countries. The saturation of scholars in Ukraine is 6 people in 1000 in the economically active population, while in Japan - 11, U.S. - 10, France - 15. This difference between Ukrainian and foreign researchers is explained by the mobility and the aging of scientists.

So, the main problems of Ukraine are the shortage of budget funds, inadequate legislation concerning the creation and development of innovation and investment environment, the lack of interest of financial institutions in supporting innovative projects and limited demand for innovative proposals. The role of science in the development of society is constantly growing, and scientists acquire the status of the most respected social group.

4 The National Academies of Sciences of Ukraine Report (2012)."Science of Ukraine. Figures, facts, problems" 


\section{REFERENCES}

Bell, D. (1973), Coming of Post-Industrial Society: A Venture in Social Forecasting (339-38)

Bourdieu, P. (1986). The forms of capital: Handbook of theory and research for sociology of Education. In: J. Richardson (Ed.). New York: Greenwood Press.

Etzkowitz, H. Leydesdorff, L., (2000). The dynamics of innovation: from National Systems and 'Mode $2^{\prime}$ to a Triple Helix of university-industry-government relations. Research Policy, 2(29) pp. ....

Florida, R. (2002). The Rise of the Creative Class: Why Cities without gays and rock bands are losing the economic development race. Washington Monthly ... Retrieved from http:/ / www.washingtonmonthly.com/features/2001/0205.florida.html.

Florida, R. (2002). The Rise of the Creative Class. And How It's Transforming Work: Leisure and Everyday Life. ... Basic Books.

Fox, M. (1992). Research, teaching, and publication productivity : mutuality versus competition in academia. Sociology of Education, 4(65).....

Ilyin, E.P. (2008). Motivation and motives. Sankt Petersburg: ......

Lam, A. (2010). What Motivates Academic Scientists to Engage in Research Commercialisation: "Gold", "Ribbon" or "Puzzle", London: Royal Holloway, University of London, School of Management.

Motyl, M., \& Spies, J. (2012), Scientific Utopia: II - Restructuring Incentives and Practices to Promote Truth Over Publishability. ...: University of Virginia. Retrieved from http://papers.ssrn.com/sol3/ papers.cfm?abstract_id $=2062465$.

Popova, I. (2010). Autonomy at work as a feature of flexible employment, Social class in the Russian society: Studies of the social classes and social change of contemporary Russia. In: J. Nikula, \& M. Chernysh (Eds.). Saarbrucken: Lambert Academic Publishing. pp. 80-103.

Shockley, W. (1957), On the statistics of Individual Variations of Productivity in Research Laboratories, Proceedings of the Institute of Radio Engineers.... 1409 p....

van Noorden, R. (2012). Global mobility: Science on the move. NATURE International weekly journal of science, ... $490 \mathrm{p} . .$.

Yudkevich, M. (2005). Professor - university relationships: Incentives for investments in joint future. HSE WP 10/2005/05. 